\title{
The application of traditional Tibetan auspicious patterns in the clothing design
}

\author{
Yugang Chen ${ }^{1, a}$ \\ ${ }^{1}$ Jiangxi Institute of Fashion Technology, Jiangxi, Nanchang, 330201 \\ a28941204@qq.com
}

Keywords: Tibetan; Auspicious patterns; Clothing design; using

\begin{abstract}
This paper analyzed the formation of Tibetan traditional auspicious patterns and the reasons, and introduces its developing process, and then focuses on the use of Tibetan auspicious patterns and the innovation points, optimizing the cultural inheritance in the field of fashion design in China has certain guiding significance.
\end{abstract}

\section{The introduction}

With the development of China's science and technology, rapid economic growth, the impact of western culture on Chinese native culture is becoming more and more intense, a lot of folk culture or even bad luck. On a global scale, costume design in our country lack of creative consciousness, and rarely will traditional culture cleverly used in fashion design, even though there are quite a few attempts, but mostly just superficial, it is hard to provoke emotional resonance. Tibetan traditional auspicious patterns have a strong artistic expression, and have strong local color, the value is quite high, so by studying the application of Tibetan auspicious patterns in the clothing design, will guide the development of clothing design in the future.

\section{The introduction of Tibetan auspicious patterns}

Auspicious patterns as the name implies, represents happiness and lucky pattern, is the important carrier of auspicious culture, through the art form to the people's moral good. Auspicious patterns based on people's world view of thinking, has the very high aesthetic value, is also a region, folk art, according to the national culture emotion, saturated with lofty ideals.

The origin of Tibetan auspicious patterns. Tibetan auspicious patterns sedimentation and evolution in the long river of time, is the embodiment of Tibetan culture, has the very high artistic value. Tibetan ancestors living environment is relatively poor, so the Tibetan auspicious patterns is also the first people to inner aspiration to express, the longing for reality demands, beyond the self, auspicious patterns according to certain form unique to Tibetan people's pursuit of beauty.

The characteristics of Tibetan auspicious patterns. Due to China's Tibet's unique geographical position, determines the Tibetan culture contained in central Asia, west Asia and South Asia and so on the many kinds of culture, and foreign culture, more long-term adhering to the selection and choice of attitude, has a rational thinking on life and life, but also there is no lack of perceptual imagination. Tibetan auspicious patterns is evolving in the process of all kinds of culture and art exchange and development, the art of han nationality, the original this teaching style under the influence of forming the unique artistic genre, design to reveal the cultural connotation is not only the feelings of anger, is the embodiment of the faith, Tibetan auspicious patterns in combination with religious and secular, design itself in affinity at the same time, profound cultural connotation. Tibetan auspicious patterns empathy, concepts of symbol and the symbol of human value, design is human-centered, showing the person contact of all things, get rid of the demand of death and pain. Tibetan auspicious patterns emphasize aesthetic and function to two or morethings, ideas and practice in combination with double blessing, body and soul, as shown in figure 1, 2 . 


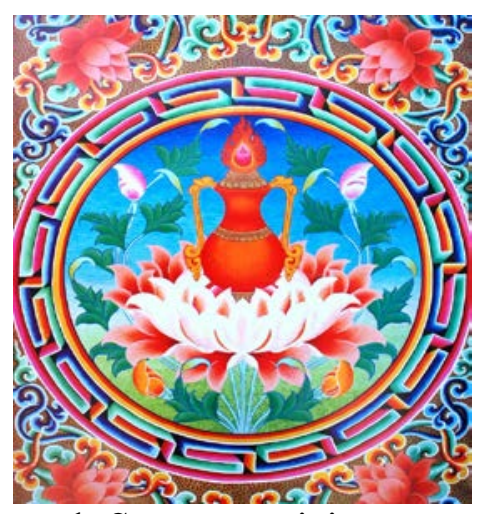

Figure 1. Sweet auspicious patterns

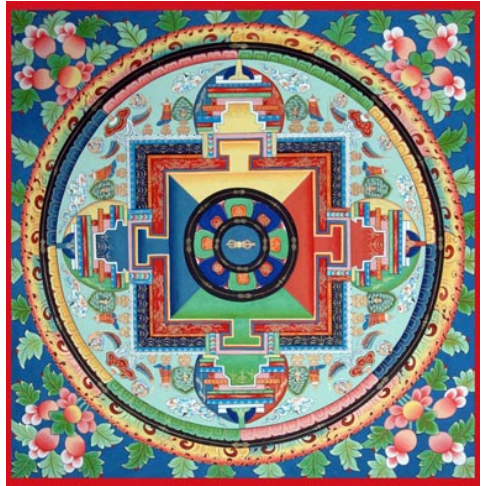

Figure 2. Tibetan thangkas pattern

The evolution of the Tibetan auspicious patterns. Tibetan auspicious patterns in the history of China has always been changing, from the primitive religion to teach protecting period, then to Buddhism buddhist period, with the influence of human on the natural increase, put more symbol design, and artistic effect.

The moral of Tibetan auspicious patterns. The moral of Tibetan auspicious patterns mainly divides into the folk moral, religious implication. The former is mainly the blessings of people's life happiness, healthy body, the latter is mainly because of Tibetan auspicious patterns to boom when Buddhism was introduced, the significance of through philosophic theory, converted for followers to buddhist.

\section{The application of traditional Tibetan auspicious patterns in the clothing design}

Through the above introduction, the Tibetan auspicious pattern has a long historical roots, evolution process is also reflected how many generation of person's painstaking care. In fact, the Tibetan clothing has a long history and local museum in Tibet is in possession of many mariko era clothing in the new period. Tibetan costumes widespread in cultural exchanges, and constantly influenced by other cultures. The Tibetan people with their wisdom and passion, injected a lot of energy to the Tibetan clothing, at present, the traditional Tibetan dress still continuously provides the inspiration for the general clothing design personnel, including the Tibetan traditional auspicious patterns play an irreplaceable role.

Clothing function adaptability analysis. Because the Tibetan is a nation of foreign culture capacity strong, continuous and outland culture blend. Since the $1990 \mathrm{~s}$, with the rapid development of business, a lot of clothing brand fashion elements into Tibet. Most of these introduced clothing is a popular brand, the agent is responsible for the management, convenient Tibetan people's life greatly without doubt. Tibetan people in the clothing when the choice of its functional consideration is more, this is determined by the local environmental condition.

Tibet has unique plateau amorous feelings, the pilgrimage every year to attract a large number of tourists sightseeing, although local culture rendered by foreign culture, but throughout ZangHan culture is the mainstream culture, the local people are always stick to the main industry of animal husbandry and agriculture, clothing brand also retain robe structure mostly, this is the most suitable for plateau form of life and production of clothing. Tibetan clothing long sleeve structure in the case of morning and evening temperature difference is great adaptability is very strong, lady's CangZhuang long sleeve in the process of wave rich aesthetic feeling.

The pluralism of the costume culture elements used. Tibetan clothing after years of development, into the pluralistic modern dress element, its characteristic mainly is to satisfy the life needs, mainly manifested in the change of the colors, fabrics, these diverse elements and coordinate CangZhuang collocation. Previous Tibetan costume culture elements are: coat, enough clothes, accessories, Tibetan robe and head. In women's clothing there will be a short waist, long sleeve shirt, the shirt often appear in the dance. Made from materials such as silk shawl. Head dress for cap or headscarf, more young and the elderly in the headscarf selection of colour difference is bigger, with elaborate more on the former headscarf, while the latter less decoration. Modern garments for 
improvement from the Tibetan robe design of traditional Tibetan dress, change the form of open collar and adornment effect, as shown in figure 3, 4.

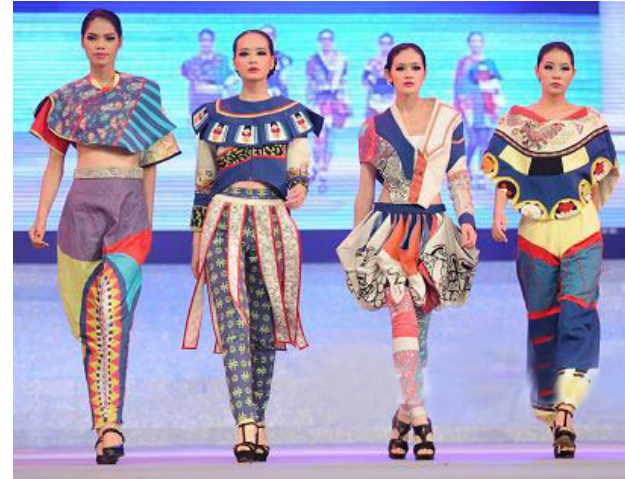

Figure 3. Design of Tibetan clothing

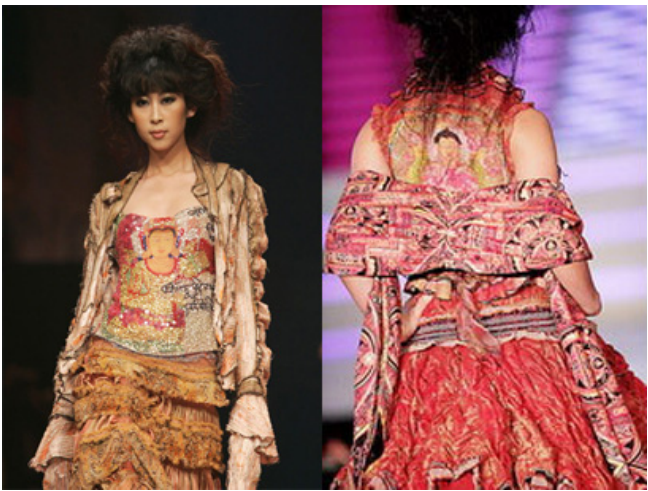

Figure 4. Design of Tibetan clothing

The aesthetic application of costume culture. The Tibetan traditional auspicious patterns applied in clothing design, must take into account and to pledge, in much of Tibetan local clothing brand, is this kind of art aesthetics, design decorative and normative pay equal attention to, efforts to adjust clothing aesthetic and functional, to achieve the physical beauty as the core.

Decorative and two kinds of properties of normative clothing is important, any CangZhuang ornamental, will decorate on CangZhuang auspicious patterns, and design the content is very diverse, from plants, animals, objects will appear, pattern of design on the basis of reality, more complete art ably deformation, show the design with vivid individuality. CangZhuang creation are either change the decorative, or change the connotation. Treasure is flower design, for example, in the process of artistic creation, the lotus and peony two completely different flowers present in the design at the same time, use the technique of art make it together, the water out of the mud without dye and in combination with the elegant peony, implied meaning is very full, coupled with back into shape, which get a complete pattern, as shown in figure 5 ..
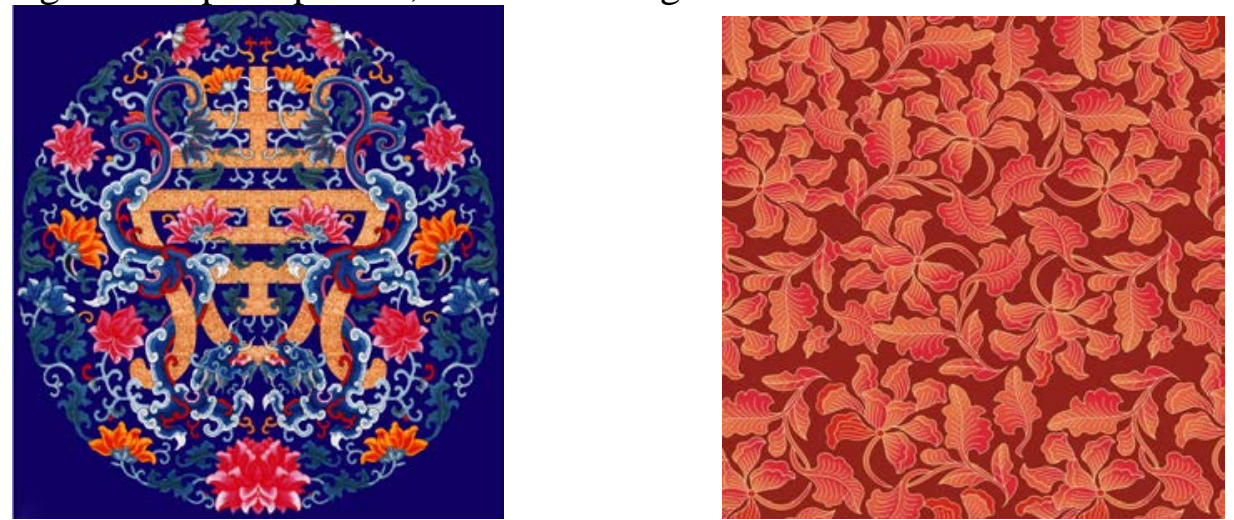

Figure 5. Treasure is flower design life of words Figure 6. Four consecutive treasure flower pattern

The application of traditional Tibetan auspicious patterns in the clothing design can take separate pattern, ground and lace three forms, the three forms of application will produce different artistic effects. Separate design suits and plain coloured dress collocation, and effect of symmetrical arrangement to the best; Ground pattern take the form of a scatter, more emphasis on freedom, pay attention to the contrast; Lace design requirements and high saturation of dress collocation, and preferably two continuous design and square continuous pattern, , as shown in figure 6. .

In the current Tibetan local clothing brand, many clothing integrated application of multivariate clothing culture elements, not only meet the functional, and realizes the dynamic and stable balance. Edging, accessories such as cooperate with local design also will get a good visual effect. Edging main effect is modify the human body, improve clothing tension, sketch the form aesthetic feeling. Many Tibetan people in his chest with stones, Tibetan auspicious decoration patterns in the cuffs. Accessories mainly refers to the head and foot wear. Due to their high Tibetan auspicious patterns 
of saturation, hue span is big, so can always from the Tibetan clothing at the same time feel showily and sedate.

Display of the clothing structure. Tibetan local clothing brand in design details the pursuit of simple, but extremely pay attention to the overall balance and stability, so the trapezoidal robe type modelling is very outstanding, in the modern fashion design can use trapezoidal garment body structure characteristic, make the garment stability to the person, the contour not only has the bright eye-catching, and full of mystery.

Dior design director Galliano used to design a dress is integrated into the connotation of Tibetan traditional auspicious patterns, will CangZhuang clothing structure performance incisively and vividly. Through the design and color of ingenious combination of point, line and plane, with the change of the texture, let a person to extrapolate. Inspired by the Tibetan robe, the structure is also taken from Tibetan robe, the garment design show the geometric decent and beautiful modelling, skillfully using geometrical piece makes whole design rich rhythm, with strong expressive force lines outline the Tibetan architectural style, rectangular waist wide structure combined with hem structure, it also edging pattern. Airfoil sleeve, sleeve length straight contact, and in the sleeve under the action of the wing, shoulder line structure above the diastolic, all show delicate. Through the analysis of the classical design of Galliano, we can find that Tibetan costume in structure characteristic is very outstanding, with the aid of the symmetry and balance, strengthen the repeated use of geometric pattern, make the garment of movement is very strong. When necessary in traditional CangZhuang structure properly handle exaggeration, more obvious feature of the structure, can make the clothing personality, stable and do not break.

\section{Conclusion}

Tibetan auspicious patterns is a cultural treasure of our country, mainly applied in the Tibetan clothing, reflect the local Tibetan desire to communicate, desire for happiness, our clothing designers should learn to taste the national culture, get inspiration, take its characteristics used in modern clothing design, inheriting the precious cultural heritage at the same time, accelerate the development of garment industry in our country.

\section{Reference}

[1] Zhou Xing. As a folk art heritage of the traditional Chinese auspicious patterns [J]. Journal of national art, 2005, 3.

[2] Su Jie. The traditional Chinese auspicious patterns in modern fashion design art [J]. Journal of silk, 2006, 6.

[3] Huang Xiaodi. The integration of China's traditional culture and the clothing design innovation [J]. Journal of neijiang science and technology, 2007, 8. 